\title{
Antenatal Diagnosis of Conjoined Twins - Parapagus Dicephalus A Case Report
}

\author{
Kasturi Mummigatti' , Aeda Shamshal ${ }^{2}$ \\ Dept of Obs / Gyn', Radiology 2 \\ Gulf Medical College Hospital and Research Centre, \\ Gulf Medical University, Aiman, UAE
}

\begin{abstract}
A case of 5 hour old, new born alive female baby laterally fused with two heads, two necks, one body with two legs and three fully formed upper arms and the $3^{\text {rd }}$ arising between the two heads with Apgar score of one and five, diagnosed antenatally and born by Em CS Section at 32 weeks to a 30 year G7P5 with previous CS, died after five hours of birth, a severe lesion such as that found in this case of dicephalus parapagus conjoined twins which is incompatible with postnatal life account for less than $0.5 \%$ of all reported cases of conjoined twins who fail to survive is brought to discussion.
\end{abstract}

Keywords: Parapagus, Dicephalus, Conjoined twins.

\section{Introduction}

Conjoined twins are a rare obstetric event occurring 1 in 50,000 to 1 in 100,000 deliveries as a result of incomplete fusion of the embryonic disc before the third week of pregnancy ${ }^{1}$. They belong to the monochorionic-monoamniotic type of monozygotic twins and are classified according to the area of union. Parapagus dicephalus (anterolaterally joined two headed) twins account for less than $0.5 \%$ of all reported cases of conjoined twins and are extremely rare $^{2-7}$. Most authors report that $70-95 \%$ of conjoined twins are female although one study cited a nearly equal male: female ratio ${ }^{2,8-10}$. We report a case of parapagus dicephalus - conjoined twins which was diagnosed antenatally and delivered by Cesarean section. This case was initially diagnosed in different centers clinically and by ultrasound as a case of twin pregnancy before a final diagnosis was made in GMC Hospital and Research Centre, Ajman as conjoined twins.

\section{Case}

A 30 year old Pakistani patient G7P5, previous cesarean section presented to Gulf Medical College Hospital and Research Centre, Ajman, United Arab Emirates (GMCHRC) for a routine antenatal check up on $30 / 07 / 2007$, at 32 weeks gestation estimated by ultrasound scan. She had irregular antenatal visits in Dubai and Sharjah. She did not know her LMP. Obstetric History revealed she was - G7P5A1 - $1^{\text {st }}$ three deliveries - Normal vaginal delivery in Al Quasmi Hospital, Sharjah, $4^{\text {th }}$ delivery was LSCS for transverse lie of weight $3.8 \mathrm{~kg}$ baby in Iranian Hospital and $5^{\text {th }}$ was normal vaginal delivery of $4.2 \mathrm{~kg}$ male baby in GMC Hospital, Ajman and current pregnancy is the $7^{\text {th }}$ one and with a history of one spontaneous abortion. She gives a past history of mild PIH in the previous pregnancy but not on any medications. History revealed no known exposures to teratogens, no known infections and no family history of congenital anomalies or twins. Clinically on abdominal examination multiple fetal parts felt with positive fetal heart beat. Patient had an ultrasound using 3.5 MHZ linear array real time scanner. Serial Scans and X-ray of the abdomen done before the final diagnosis of conjoined twins was made (Fig 1).

\section{Correspondence}

Dr. Kasturi Mummigatti MD

Associate Prof. Dept of Obs / Gyn

Gulf Medical College Hospital and Research Centre,

Gulf Medical University, Ajman, UAE

Phone: +971-6-7463333

Email : researchdivision@gmu.ac.ae 


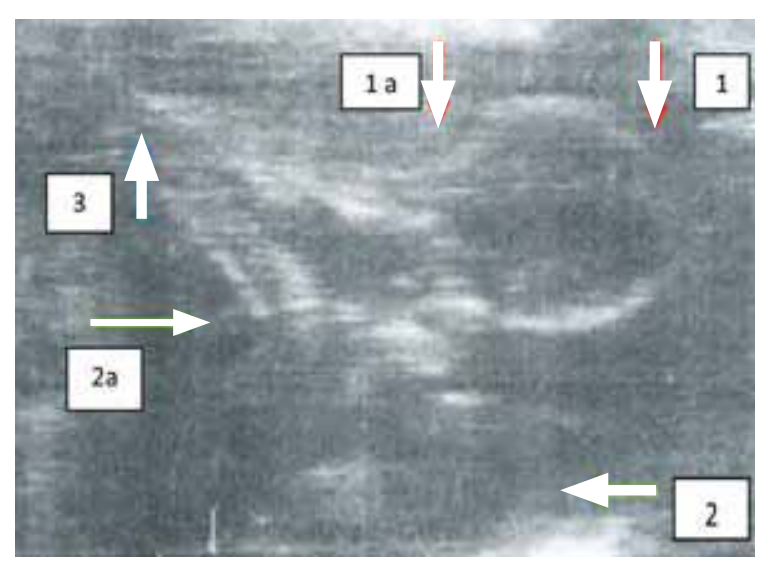

Fig 1. Prenatal $X$-ray showing two heads with fusion at the thoracic region $1 / 1$ a shows head and neck. 2/2a shows the other head and neck. 3 shows Fusion of the 2 necks at the mid thoracic region.

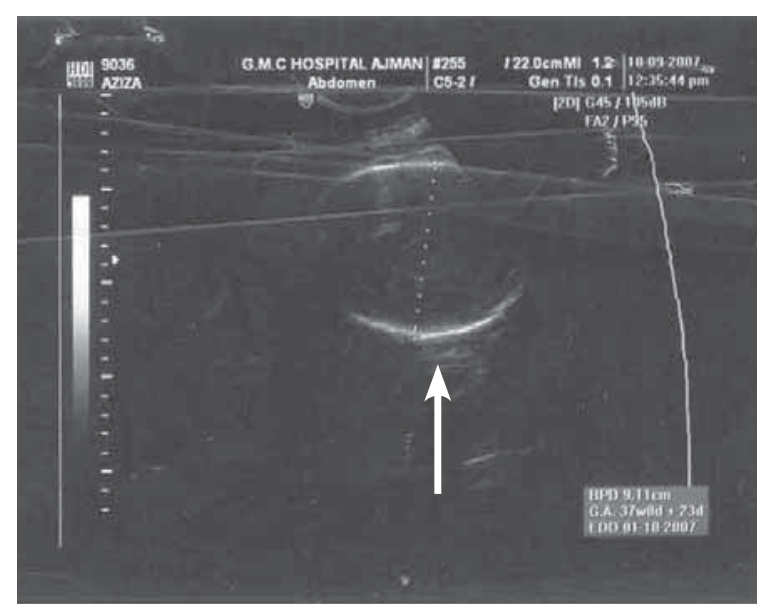

Fig 2b. USG showing BPD of one of the fetal head.

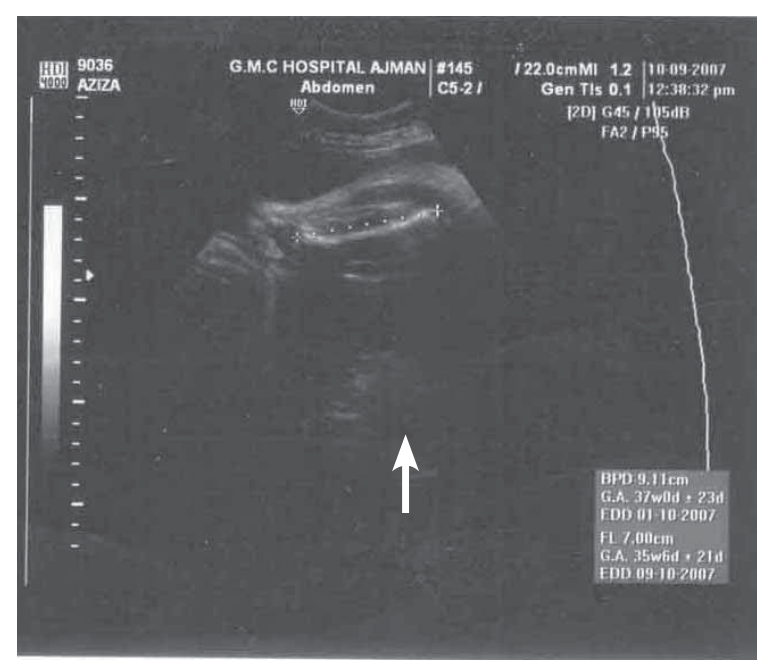

Fig 2d. USG showing Femur length

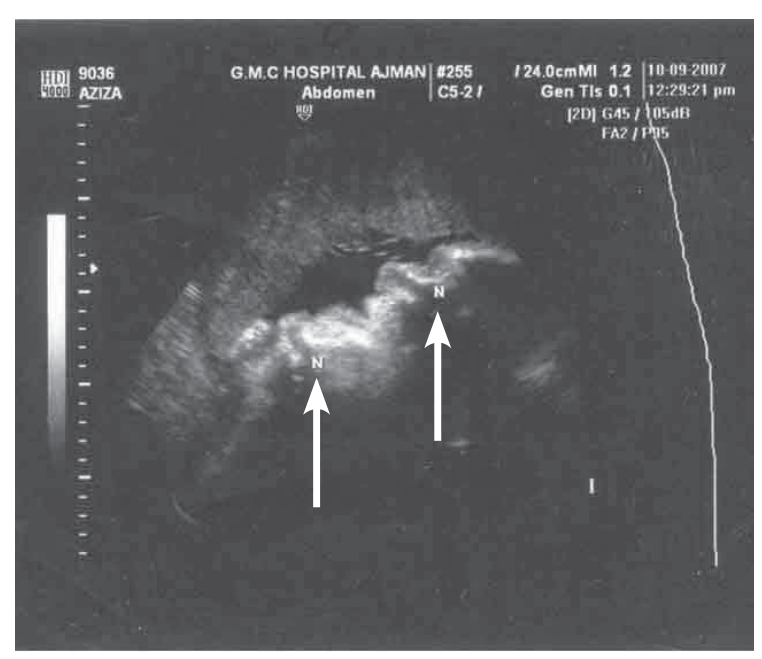

Fig 2a. USG showing two faces

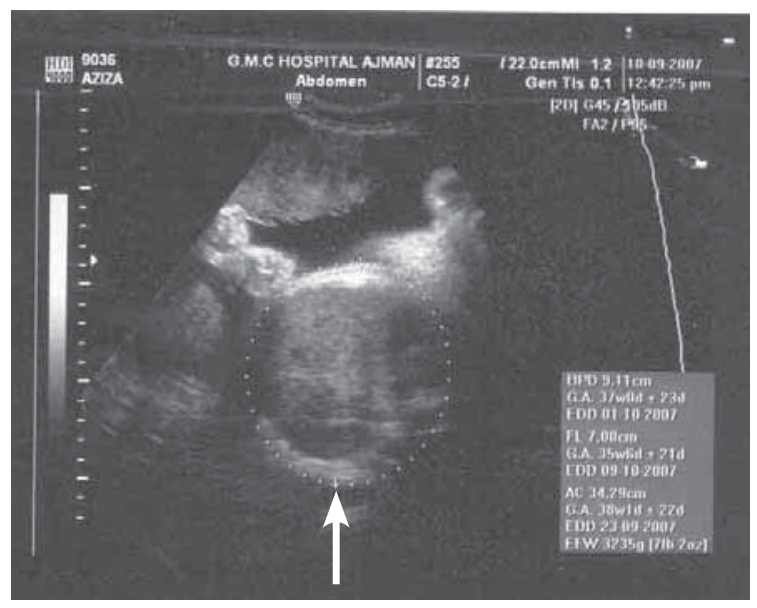

Fig 2c. USG showing abdominal circumference of the body which is single.

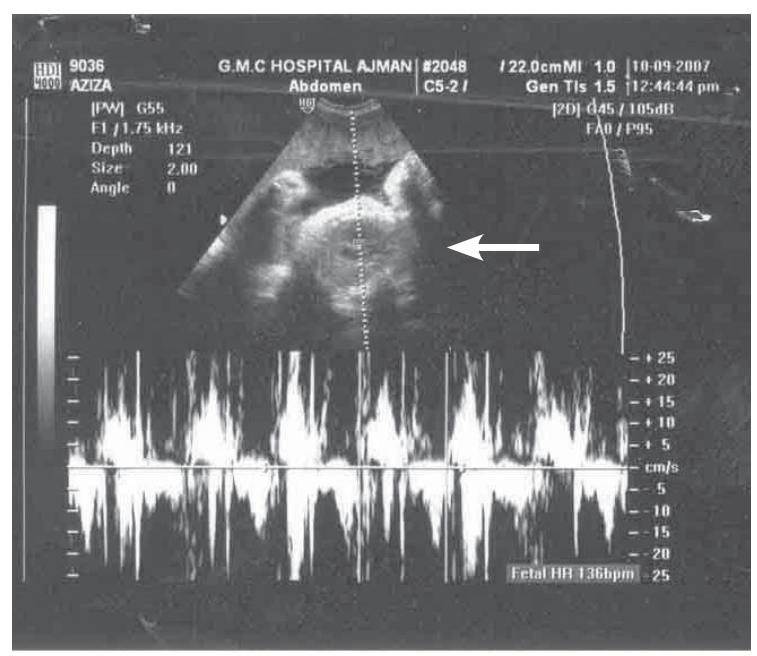

Fig 2e. USG showing single fetal heart 
The most significant ultrasound findings included the demonstration of a single heart beat having regular cardiac activity in a conjoined twins with 2 heads, 1 body, 2 cervical spine fused near the mid thoracic regions, 2 lower limbs and 3 upper arms and the $3^{\text {rd }}$ arm most probably arising between the 2 heads (Fig 2). Single fetal stomach and single fetal urinary bladder was seen and single placenta present at the anterior and fundal region. The amniotic fluid volume was within normal limits. The patient was informed about the rare form of conjoined twin and was counseled. Ultrasound played a crucial role in the diagnosis and establishing the degree of conjoining.

Patient posted for Elective Cesarean section but had an emergency LSCS and delivered an alive female baby weighing $5.8 \mathrm{~kg}$ at $12.10 \mathrm{pm}$ on $12 / 10 / 07$. The neonate had laterally fused 2 heads, 2 necks, 1 body with 2 legs and 3 fully formed upper arms and the $3^{\text {rd }}$ arising between the 2 heads (Fig 3) with apgar score of one and five, the baby died in NICU after five hours of birth at $5.10 \mathrm{pm}$. [Female genitalia was well formed. The placenta was monochorionic-monoamniotic weighing 570 grams.] Post operative period was uneventful and patient was discharged in good condition after 3 days.

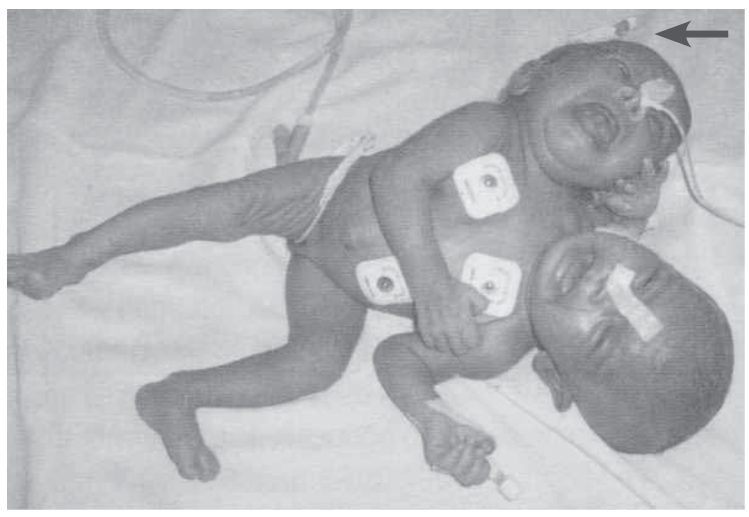

Fig 3. Female Conjoined Twin laterally fused with 3 arms, 2 legs and red arrow shows third arm.

\section{Discussion}

Spencer proposed a classification for anterolaterally conjoined twins which are widely accepted now, Dicephalus (two heads) and Diprosopus (two faces) cases ${ }^{11}$. Dicephalus and diprosopus twins comprised $11.2 \%$ of conjoined twins in Machin's review and $13 \%$ in the Latin American Collaborative study ${ }^{2-3}$. The authors' Medline search revealed only four references to human parapagus twins and a search on "dicephalus conjoined twins" yielded only 48 human citations since 1959. According to this the present case was classified as Parapagus decephalus with further specification as tribrachii bipedus conjoined twins. Conjoined twins are always derived from one fertilized ovum and are monochoronic (shared placenta) and monoamniotic (shared amniotic sac) ${ }^{12}$. They occur once in every 2,800 to 250,000 births, with incidence usually cited as 1 per 50,000 to 100,000 deliveries ${ }^{13}$. They may be more common in parts of Asia and Africa ${ }^{14}$. Incidence is $1: 192,000$ in southern Africa. 1:33,000 to $1: 165,000$ in North America 1: 100,000 in Japan, 1:75,000 in Sweden and Latin America. 1:68,000 in Hungary, 1: 14,000 in Africa and 1:6,500 in Taiwan ${ }^{2}$. Increased prenatal detection of Conjoined twins with ultrasound may explain an apparent rise in occurrence ${ }^{15}$. But in a few reviews they comprised between $11-13 \%$ of conjoined twins.

The increased incidence of conjoined twinning may have genetic causes. In Western Countries 1:50,000 - 1:200,000 births whereas in South East Asia and Africa, it is $1: 14,000-1: 25,000$ births. The reasons for this difference are unknown. Females conjoint twins are more up to $70 \%-95 \%$ and $60 \%$ of conjoined twins are stillborn $40 \%$ of the live at births but they die within few days.

The two main categories are symmetrical or equal conjoined twins (i.e. two well-developed babies) and asymmetrical or unequal conjoined twins (i.e. a small part of the body is duplicated or an incomplete twin is attached to a fully developed twin). In broad terms, conjoined twins may be regarded as a doubling anomaly. The later the incomplete embryologic separation occurs, the higher the likelihood of a complicated fusion. Most of them do not survive.

Two embryological theories explain conjoined twinning. The incomplete fusion of single embryonic disc occurs after 13-15 days of fertilization or a fertilized ovum completely dividing into two embryonic discs whose secondary fusion result in their unusual proximity as the embryos enlarge. Most conjoined twins face each other but parapagus dicephalus twin's axes are side by side and nearly parallel.

Although autopsy was not permitted in our case, other parapagus twins have had characteristic findings such as fused heart with complex anatomy like right aortic arch transportation of great vessels and two hearts with one malformed heart have been described. Situs inversus of the right twins abdominal organs often accompany cardiac anomalies and the abdominal viscera are normally situated when the hearts are normal. Two sets of lungs are usually present which may be underdeveloped and anomalous. The liver, pancreas, gall bladder, rectum and genitourinary tracts may be shared. 
Diagnosis of conjoined twins before birth allows practitioners to minimize injury by planning a suitable delivery $^{12}$. Therefore, careful ultrasound examination is recommended for all suspected twins ${ }^{12}$. First or second trimester detection of conjoined twins enable obstetrician to counsel parents about potential termination, or about delivery and treatment options if pregnancy is continued ${ }^{15}$.

Diagnostic challenges: Where access to technology is limited, as in our case, antepartum diagnosis of conjoined twins may be nearly impossible. Prenatal identification of conjoined twins was rare before ultrasonography was available. Sometimes twins are unsuspected at delivery of conjoined twins while auscultation, palpation and even ultrasound suggest separate twins at other times.

Three dimensional ultrasound, magnetic resonance imaging, echocardiography, or computed tomography before birth and angiography, cardiac catheterization, radionuclide, scanning, cystography or urethrography and gastrointestinal contrast studies after birth, may clarify the degree of conjoining the potential for separation and the ideal obstetrical and perinatal management ${ }^{15}$. Fetal echocardiography may miss transportation of great vessels and abnormal atria or pulmonary vascular connections but the good buffer for imaging provided by amniotic fluid may permit better visualization than postnatal echocardiography ${ }^{12,13,15}$.

Prognosis: In general, few conjoined twins survive due to heart, lung, abdominal and neurological malformations often present even in unshared structures $^{13,15}$. Roughly $40 \%$ of conjoined twins are stillborn and $35 \%$ die in the first 24 hours of life Moreover only $60 \%$ of surgically treated conjoined twins survive. A retrospective tertiary center review found only 5 survivors out of 14 pairs of conjoined twins, a survival rate of $18 \%{ }^{15}$. Still birth and mortality rate are extremely high in dicephalus twins dibrachius (two arms) dicephalus twins had a remarkable 11 day survival $^{12,15}$. Rare three and four arm dicephalus twins live to adulthood ${ }^{6}$.

Delivery: There are many reported vaginal deliveries of conjoined twins ${ }^{14}$. Although compressible fetal tissues may facilitate vaginal birth, dystocia uterine rupture or maternal soft tissue injury can occur when conjoined twins are identified before birth, Cesarean section is preferred to avoid maternal trauma and to facilitate treatment of viable neonates ${ }^{13}$.

There are three management options:1) Withholding or withdrawing life support to allow both twins to die. 2)
Separating the twins, with the possibility that one will die or 3) Allowing twins to remain conjoined. This does not apply to parapagus twins, whose extensively shared organs preclude survival or acceptable quality of life. When separation of conjoined twins is not immediately required, surgery is usually delayed until late infancy, to permit careful preoperative evaluation and better tolerance of surgery ${ }^{13,15}$. Intervention is sometimes needed at birth or within 24 hours ${ }^{15}$. Separation of a pair of tribrachius (three-arm) dicephalus twins resulted in one infant's death ${ }^{6}$ and dicephalus twins generally are stillborn or only live a few hours, so comfort measures may be most appropriate for them.

Ethical issues are thus often urgent ${ }^{16}$. Sanctity and quality of life for each twin are primary concerns ${ }^{14}$. Multidisciplinary committees are best suited to consider the medical, social, cultural, religious and legal implications of management options ${ }^{16}$. Clinicians must involve parents in decisions soon after diagnosis and can encourage them to consult counselors and clergy $^{16}$. Courts may become involved ${ }^{16}$. Society may assume conjoined twins are two people who wish to survive regardless of bodily form, with a preference for separate existence ${ }^{16}$. However, some adult conjoined twins prefer to remain attached rather than to risk death or an inferior quality of life ${ }^{16}$ thus, separation is not always desirable ${ }^{16}$.

Professionals must protect the confidentiality of families with conjoined twins ${ }^{16}$. Societal condemnation as feared by the family in our case, may occur either locally as a negative reaction to an anomalous birth, or worldwide as the media criticize a private decision ${ }^{16}$. Obstetricians must not abandon patients after delivery. Empathic counseling for decisions, similar to that given to parents of anomalous singletons, can be offered, with bereavement support if one or both babies die.

\section{Conclusion}

Conjoined twins are rare and parapagus dicephalus twins represent only a small proportion. Anomalies of the heart and abdominal organs occur in most dicephalus twins. Early diagnosis, facilities for termination or optimal obstetric and perinatal preparation is required. Practitioners may unexpectedly encounter conjoined twins at delivery. If no antenatal studies were performed in suspected twins, practitioners can obtain an ultrasound to rule out conjunction before delivery. Ethical issues surrounding separation do not apply to parapagus twins, whose extensively shared organs preclude survival or acceptable quality of life. 


\section{References}

1 Spitz L, Kiely EM. Conjoined Twins. JAMA 2003; 289:1307-10.

2 Castilla EE, Lopez-Camelo JS, Orioli IM, et al. The epidemiology of conjoined twins in Latin America. Acta Genet Med Gemellor 1988; 37:111-8.

3 Machin GA. Conjoined twins: implications for blastogenesis. Birth Defects Orig Artic Ser 1993; 29:141-79.

4 Yang CC, Kuo RC, Yang HB, et al. Prenatal diagnosis of dicephalic conjoined twins: report of a case. J Formos Med Assoc 1994; 93:626-8.

5 Groner JI, Teske DW, Teich S. Dicephalus dipus dibrachius an unusual case of conjoined twins. J Pediatr Surg 1996; 31:1698-700.

6 Bendeson J. Dicephalus conjoined twins: a historical review with emphasis on viability. J Paedtr Surg 2001; 36:1435-44.

7 Tansel T, Yazicioglu F. Cardiac and other malformations in parapagus tiwns. Arch GyneCol Obstetr 2004; 269:211-3.

8 Puzzio JJ, Ganesh V, Landau I, et al. Prenatal diagnosis of conjoined twins. Am J Obstet Gynecol 1984; 148:343-4.
9 Barth RA, Filly RA, Goldberg JD, et al. Conjoined twins prenatal diagnosis and assessment of associated malformations. Radiology 1990; 177:201-7.

10 Barness EG, Spicer DD, Opitz JM. Conjoined twins morphogenesis of the heart and a review. Am J Med Genet 2003; 120:68-82.

11 Spencer R. Conjoined twins: theoretical embryologic basis. Teratology 1992; 45:591-602.

12 Hammond DI, Okun NB, Carpenter BF, et al. Prenatal ultrasonographic diagnosisnof dicephalus conjoined twins. Can Assoc Radiol J 1991; 42:357-9.

13 Bianchi DW, Crombleholme TM, D'Alton ME. Conjoined twins. In, Bianchi DW \& D'Alton ME (ed). Foetology: The Diagnosis and Management of the fetal patient, $1^{\text {st }}$ edition. New York, McGraw Hill 2000; 893-9.

14 Shija JK, Matekere NJ, Massawe AW. The conjoined twins of Shinyanga, Tanzania: case report. East Afr Med J 1994; 71:751-4.

15 Mackenzie TC, Crombleholme TM, Johnson MP, et al. The natural history of prenatally diagnosed conjoined twins. J Pediatr Surg 2002; 37:303-9.

16 Atkinson L. Ethics and conjoined twins. Childs Nerv Syst 2004; 20:504-7. 